\title{
europhysics news
}

March/April 1995

Vol. 26 , No. 2

\author{
The Spreading of Droplets on Solids \\ by K. Kaski
}

A Transferable Tight-Binding Potential

for Transition-Metal Silicides

by L. Miglio

EURO-CRYST:

A New Initiative for Crystal Growth

nordic focus

Nordic Cooperation Scrutinized

- Theoretical Physics

- Industrial R\&D Cooperation

- Cooperation with the Third World

publications

Preparing for a Phase Change

Scientific Publishing without Publishers

Reflecting an Enlarged Community

Journal Exchanges

facilities and organizations

EUPRO; OECD; US spallation source;

Nuclear Council

THE NETHERLANDS: Pressure on Research

from Several Sides

PHARE PROGRAMME:

The Role of Science in the Reform Process

information to eps members

EPS COUNCIL: Positive Launch of a New Phase

Council and Executive Committee Decisions

\section{European Physical Society}

Europhysics News is the bulletin of the European Physical Society, published at least six times each year. Subscription price: SFR 135.-p. a.

\section{Editorial Board}

P. Bochsler, Bern University

S. Ciliberto, ENS, Lyon

A.-J. Dianoux, ILL, Grenoble

Editor: P.G. Boswell

Exec. Sec.: G. Thomas

\section{Editorial and Advertising}

EPS Secretariat, P. O.Box 69

$\mathrm{CH}-1213$ Petit-Lancy 2, Geneva

Telephone: $\quad+41(22) 7931130$

Telefax: $\quad+41(22) 7931317$

E-mail: peter.boswell@cern.ch

Advertising is charged according to space on a sliding scale ranging from SFR 2700.- for a full page to SFR 700.- for a one-sixth page. Rates for four-colour and cover advertising and for series insertions on request. Special rates for EPS Associate Members; $25 \%$ reduction for situations vacant.
T. Jarlborg, Geneva University

R. Poerschke, Berlin

J. Schacher, Bern University

M. Siegrist, EPFL, Lausanne

President: H. Schopper, CERN

\section{Deadline for advertising orders} First week of month of publication.

Subscriptions \& EPS Fees

Société de Banque Suisse,

Geneva; Acc. No. 164.899

Swiss Post Office Acc.: CCP

Geneva 12-19107-4

German Post Office Acc.: Postbank

Karlsruhe 1801-30-754

Eurocheque to EPS, Geneva

EPS Budapest Secretariat

Telephone: $\quad+36$ (1) 1173510 Telefax: $\quad+36(1) 1176817$
Nádor u. 7, H-1051 Budapest

\section{Cover illustration}

Single crystals of mercury iodide are candidates for room-temperature semiconducting detectors. They can be grown at present to up to $1000 \mathrm{~g}$ in weight using vapour-phase methods. Fundamental studies in the context of the proposed EUROCRYST initiative would aim to elucidate the origins of defects for positively charged carriers that currently limit the application of this novel material (see page 28).

\section{Full Steam Ahead}

Mark Siegrist who chairs the Editorial Board discusses the development of Europhysics News.

Discussions have been held in EPS committees for some time on how to improve the appeal of Europhysics News, the single most visible sign of the existence and activities of the European Physical Society. There has always been general agreement that EN should one day become THE European bulletin for the physics community, and play a role somewhat similar to that of Physics Today. However, the stumbling block has always been the financial situation which at best allowed for adiabatic grow.

Several attempts to render Europhysics News more attractive have been made over the years by changing the layout, general format and structure. Scientific articles were introduced in Volume 5 and right from start they been appreciated for their quality. Authors have always been carefully selected in order to produce interesting reports on scientific achievements in a form which can easily be digested by non-experts. When rubriques were introduced or the importance of existing ones emphasized, one always tried to do this in addition to, and not instead of, scientific articles.

It was a hard blow when the Executive was obliged to reduce the number of issues published each year from 10 to a minimum of six. All other available means of equilibrating the Society's budget having been exploited, it had become unavoidable to curtail the expenditure on $E N$ following the introduction of the National Society Member category which led to circulation doubling.

The idea cropped up to try to restore the health of the bulletin by collaborating with a commercial publisher. As a result of detailed discussions, an offer of Springer-Verlag has been retained which foresees a financial infusion for a three-year test period, during which time the financial balance should be restored. Further discussion will see if Springer should take over production and try to increase revenues, with full editorial responsibility remaining with EPS.

As the first visible signs of the collaboration, the Springer label now appears on the front cover and R. Poerschke joins the Editorial Board. The Editor is also introducing more rubriques as these will become the basis for a larger and more appealing magazine addressing a broader audience.

Great optimism stimulates the Executive as well as the Editor and his Board to make an all-out effort to guarantee the success of this new venture one which may eventually allow us to realize the years'-old dream of a substantial and high-quality bulletin for all of Europe's physicists. 